\title{
Cost-benefit model in improving traceability system: case study in Indonesian bulk-liquid industry
}

\author{
Ivan Gunawan, Iwan Vanany \& Erwin Widodo
}

To cite this article: Ivan Gunawan, Iwan Vanany \& Erwin Widodo (2019): Cost-benefit model in improving traceability system: case study in Indonesian bulk-liquid industry, Supply Chain Forum: An International Journal, DOI: 10.1080/16258312.2019.1570671

To link to this article: https://doi.org/10.1080/16258312.2019.1570671

曲 Published online: 28 Jan 2019.

Submit your article to this journal $\pi$

View Crossmark data $\asymp$ 


\title{
Cost-benefit model in improving traceability system: case study in Indonesian bulk-liquid industry
}

\author{
Ivan Gunawan ${ }^{\mathrm{a}, \mathrm{b}}$, Iwan Vanany ${ }^{\mathrm{a}}$ and Erwin Widodo ${ }^{\mathrm{a}}$ \\ aDepartment of Industrial Engineering, Institut Teknologi Sepuluh Nopember, Surabaya, Indonesia; bepartment of Industrial \\ Engineering, Universitas Katolik Widya Mandala Surabaya, Surabaya, Indonesia
}

\section{ABSTRACT}

Traceability system (TS) is a part of a food safety management system to support efficient food recall process. Building a TS for bulk-liquid food industry has been identified as the most difficult task due to its operational characteristics. This paper captures the real phenomenon of TS and food recall in three edible oil industries in Indonesia. Cross-case comparison shows that the TS practices in similar industries may vary. Although, their TS proves to have an effect on their capability to recall, building an excellent TS is costly. Therefore, a cost-benefit model based on a system dynamic approach is proposed to assist the industry in setting the traceability improvement program. The cost-benefit model considers the influence of traceability dimensions on profit and recall cost. The cost-benefit conceptual model is presented in a causal loop diagram. Then, the stock flow diagram runs the simulation improvement scenarios in real case. Scenario 3 is chosen as the best short-term TS improvement program.

\section{KEYWORDS}

Bulk-liquid industry;

cost-benefit model; food recall; traceability system

\section{Introduction}

A food industry with a guaranteed food safety management system used to have an added value in the business. However, the increased intensity of food recalls, which have occurred in recent years have forced the food supply chain to comply with food safety regulations and standards (Dani 2015). Nowadays, implementing a food safety management system has become a must for the food industry in order to maintain its business (Trafialek and Kolanowski 2017). Due to the additional cost, many industries may experience a financial burden from the implementation of the food management system standard (Taylor 2001). Nevertheless, Trienekens and Zuurbier (2008) argued that the implementation of food safety management systems would improve production efficiency, lower the cost of goods and expand market access. Thus, the implementation of the food safety management system is a win-win solution for the food industry itself and its customers.

One of the standards for food safety management systems, which is commonly implemented by food industries, is ISO 22000. When an industry has chosen to implement this standard, it must follow a repetitive cycle to maintain compliance with standard requirements and improve the quality of management system implementation. By following this cycle, the industry will always have room for improvements. The requirement for making continuous improvement is described in clause 8.5 ISO 22000:2005. The industry is free to choose the improvement methods or programs, which are suitable for its conditions in order to comply with the requirements set by the standard. The audit process will then determine how far the requirements have been fulfilled and how consistently the industry executes the methods or programs.

In principle, the food safety management system is not intended to eliminate risks but to control and minimise risks. Therefore, an industry is not only required to meet the regulations and perform sanitation practices in its factories but also to develop a sustainable plan to improve the effectiveness of food safety management systems and to address food safety incidents such as food recalls. A food recall should be done when there is a food safety or quality issue as part of corporate responsibility to protect consumers (Kumar 2014). Hora, Bapuji, and Roth (2011) and Ni, Flynn, and Jacobs (2014) stated that a recall process is a reverse supply chain. However, it is a particular reverse supply chain activity that does not provide any added value to the industry and causes financial losses for food industries. The food industry's capability in handling incidents will affect the extent of its losses. Food recall handling is explicitly described in clause 7.10.3 and 7.10.4 ISO 22000:2005.

A traceability system (TS) is part of the requirements of a food safety management system which an industry must build in order to support food recall handling. Karâa and Morana (2016) mentioned that a TS facility is the first step in planning a targeted and efficient food

CONTACT Iwan Vanany vanany@ie.its.ac.id $\Theta$ Industrial Engineering Department, Institut Teknologi Sepuluh Nopember, Jalan Raya ITS Sukolilo, Surabaya 60111, Indonesia

2019 KEDGE Business Schoo 
recall process. The requirement for food industries to establish an appropriate TS is described in clause 7.9 ISO 22000:2005. Traceability is also known as a robustness factor of the six Ts (Traceability, Transparency, Testability, Time, Trust, and Training) in building food quality in a supply chain context (Roth et al. 2008). Furthermore, International Organization for Standardization (2005) in ISO 22000:2005 described that the TS must be able to identify incoming materials from direct suppliers and the initial distribution route of the end product. This indicates that the minimal requirement for industries is to hold one-step-forward and onestep-back traceability (Zhang and Bhatt 2014).

The issue of additional costs is one obstacle in building an excellent TS, especially for the food industry in developing countries (Banerjee, Menon, and Ramful 2015). Furthermore, customers are often pricesensitive in their purchasing decisions, which means that it is important that traceability costs not affect product price. Therefore, the food industry needs to choose a traceability improvement scenario which can provide more benefits than costs. The cost-benefit model can be used to test possible scenarios for the continuous improvement of TS.

Studies on the cost-benefit of TS implementation have been conducted in various types of food chains, such as: the dairy processing industry (Sparling et al. 2006), animal products (Roth and Dolschitz 2007; Rehben 2015), mineral water companies (Chryssochoidis et al. 2009; Mari Karlsen, Olsen, and Donnelly 2010), fishery products (Mai et al. 2010; Donnelly, Thakur, and Sakai 2013; Asioli, Boecker, and Canavari 2014), and eggs (Li 2013). Technological advancement inspired Aiello, Enea, and Muriana (2015) and Zhu (2017) to calculate the costs and the benefits of RFID (Radio Frequency Identification) implementation on perishable product traceability such as fruit and vegetables. However, these studies have not discussed the costbenefit of improving TS in the bulk-liquid food industry. In fact, the challenges when improving the TS are the characteristics of product and the types of packaging. Industries which have a continuous product such as a liquid (Skoglund and Dejmek 2007) and sell their product in bulk (non-packaged product) (Thakur and Hurburgh 2009) are classified as the most challenging type of industry in building TS. Therefore, we proposed the following research questions:

$R Q 1$. What is the bulk-liquid food industry perspective on traceability and food recall?

$R Q 2$. How effective is the cost-benefit model in assessing TS improvement scenarios?

A cross-case comparison of three edible oil industries was conducted to address these research questions. Edible oil is a liquid product which is usually traded as a commodity in bulk. The product may contain substances that allow the occurrence of food safety hazards, such as polycyclic aromatic hydrocarbons (PAHs). PAHs consist of organic pollutants that may trigger cancer. A study conducted by Shi, Zhang, and Liu (2016) showed that from 85 samples taken of edible oil products in China markets, 11 samples had PAH content that exceeded the threshold. This finding has driven us to investigate the conditions of the TS and its impact on food recall.

In-depth interviews were conducted to capture the industry's perspective on the issues. The results were then analysed using a grounded theory approach. The Granularity Evaluation Model (GEM), which was developed by Qian et al. (2017), was employed as a framework to observe TS based on three dimensions: precision, breadth, and depth. The data and information were used to build a cost-benefit model and to generate possible scenarios for improving TS.

The edible oil industry is a commodity business which is identical with a small profit margin. Therefore, when selecting an improvement scenario, cost-effectiveness needs to be considered. We hypothesise that not all improvements in the dimensions of TS will deliver a significant impact in the short-term. This paper presents a system dynamics simulation model of cost-benefit in improving TS in the Indonesian bulk-liquid food industry. The result of this study is a cost-effective TS improvement scenario to support an efficient food recall process.

\section{Literature review}

\section{Food recall}

A food recall is defined as 'an action to withdraw food products that have the potential to cause health problems and/or does not comply with the laws and regulations of each stage of the food chain, including food products that have been purchased by consumers, in an effort to provide protection to consumers' (Regulation of the Head of National Agency for Drug and Food Control [NADFC], 2017). This definition shows that recall is an umbrella term for many types of recall action such as consumer recall, withdrawal/ trade recall, and stock recovery. Table 1 explains further about the recall classification based on the stage of the food chain, recall initiator, and recall size.

There are two perspectives related to food recall: consumer and government versus the food industry. The consumer and government perspective is that a food recall is an effective way to eliminate the source of the problem and to prevent the spread of the problem (Li et al. 2017). By contrast, the food industry categorise a food recall as a disaster that can cause unpredictable losses (Lu and Zhang 2010). Even a strict food safety management system cannot guarantee an industry immunity from a food recall. There will always 
Table 1. Recall types.

\begin{tabular}{|c|c|c|}
\hline Based on & Classifications & Explanation \\
\hline \multirow[t]{3}{*}{$\begin{array}{l}\text { Stage of food } \\
\text { chain }\end{array}$} & Consumer recall & $\begin{array}{l}\text { The product has been available for sale to final consumers or the final consumer has taken possession (FSANZ } \\
\text { 2014). }\end{array}$ \\
\hline & $\begin{array}{l}\text { Withdrawal/trade } \\
\text { recall }\end{array}$ & The product is still in the distribution chain and has not reached the final consumer (FSANZ 2014). \\
\hline & Stock recovery & $\begin{array}{l}\text { The product is still under the control of the company and has not been in the distribution chain (Jansen-Vullers, } \\
\text { van Dorp, and Beulens 2003). }\end{array}$ \\
\hline \multirow[t]{2}{*}{ Initiator } & Voluntary recall & Initiated by the manufacturer (NADFC 2017). \\
\hline & Mandatory recall & Mandated by the NADFC (NADFC 2017). \\
\hline \multirow[t]{3}{*}{ Size } & Total recall & All products produced within a certain time range (Kumar 2014). \\
\hline & Partial recall & Only on certain product batches from the food chain (Kumar 2014). \\
\hline & Preventive recall & Only at a specific location or specific point (Kumar 2014). \\
\hline
\end{tabular}

be potential failures that affect food quality and safety throughout the food chain (Min 1989).

The United States Department of Agriculture Food Safety and Inspection Service (USDA FSIS) database shows an upward trend in food recall. In 2005 there were only 53 recalls but in 2017 the number had doubled to more than 100 recalls (FSIS 2017). A reliable TS is considered capable of preventing a massive recall thereby significantly reducing recall cost (Kumar and Budin 2006). Therefore, the food industry needs to improve its TS in order to reduce the negative financial impact of a recall.

\section{Traceability system performance}

Primarily, a TS outlines how to determine a product's status, the processes that a product has passed through, and product movement history during the transaction (Sahin, Dallery, and Gershwin 2002). However, based on a benchmark study conducted by Van der Vorst (2004), the inequality of the TS among food industries occurred because the official body had not set clear requirements.

According to Sahin, Dallery, and Gershwin (2002), an effective and efficient TS should be able to deliver accurate, timely, complete, and consistent information about a product. Some criteria to assess a TS include the degree of detailed information, the number of links in the supply chain that can be traced back and forward, the degree of automation, the time needed for tracing, and the reliability of the tracing (Sahin, Dallery, and Gershwin 2002; Van der Vorst 2004). However, Bendaoud, Lecomte, and Yannou (2007) noted that these performance criteria had not been accompanied by a measurement protocol to quantify them.

Bendaoud, Lecomte, and Yannou (2007) developed a performance model based on twelve criteria which included five beneficiaries (government bodies, customers, suppliers, internal beneficiaries, and final consumers) and three dimensions (upstream, internal, and downstream). Dabbene and Gay (2011) preferred to use recall cost to measure TS performance.
In the traceability information system, Nääs et al. (2015) assessed performance using five indicators, namely error introduction, loss of the device, data processing, loss of data, and user satisfaction. While Kang, Park, and Youm (2016) specifically developed a query-level performance model to measure the response time of the traceability query algorithm.

GEM is a TS performance assessment model developed by Qian et al. (2017). The 'granularity' term was adapted from information systems theory to explain all dimensions of TS. Unlike the previous models that only evaluated a part of the TS, GEM considered all dimensions of the TS: precision, breadth, and depth. According to Golan et al. (2004), precision reflects the degree of assurance that the TS can indicate the movement or characteristics of particular food products. Breadth describes the amount of information that the TS can record. While depth is about how far the system can track or trace the food products. Also, GEM can generate a standardised TS performance score which is comparable and easy to interpret.

\section{Methodology}

\section{Research design}

The Indonesian food industry has experienced several food recalls and needs a suitable approach to reduce losses (Vanany and Zailani 2010). Therefore, this study was conducted to determine the influence of TS improvement in the Indonesian food industry toward the effectiveness and efficiency of the recall process. Cross-case comparison and a system dynamics approach were employed to accommodate the research issue.

Semi-structured interviews with three insiders and observations of three edible oil industries were used to collect the information for the multiple cases. Since the focus was the bulk-liquid food industry, the industries were selected by convenience sampling and represented each industry scale. Case 1 represented a smallscale industry, Case 2 represented a small-medium-scale industry, and Case 3 represented a large-scale industry. The three insiders were not chosen randomly but through selection by conducting pre-interviews with three to four candidates from each industry. The most 
capable candidates were selected to represent each case perspective.

Interview results were extracted using a grounded theory approach. Text analysis was performed using word processing software in three steps. First was open coding which was the process of identifying exciting persons, objects, or concepts from the interview transcripts. The second was axial coding which was the process of finding a relationship between open codes. The third was selective coding. Heuristics in conducting selective coding saw generality across different interviewees.

TS performance of each case was observed using GEM. Structurally, GEM consists of two-layer indicators (see Figure 1). The first layer consists of precision, breadth, and depth. On the second layer, precision is represented by external trace unit (ETU), internal flow unit (IFU), and identifiable unit conversion (IUC). Breadth is represented by information collection content (ICC) and information update frequency (IUF). Depth is represented by backward tracing distance (BTD) and forward tracking distance (FTD). Each indicator has a weight obtained from 30 experts in agriculture (Qian et al. 2017). The weight is then multiplied by 'the TS score of each case' and '20 as a constant so that the final score will have a range of value between 20 and 100 .
System dynamics (SD) has been widely used for cost system modelling such as to see cost factors that affect quality cost (Kiani et al. 2009) and to find a trade-off between service quality and cost (Kim and Wook Kim 2010). SD was considered as an appropriate modelling method for building cost-benefit models because it can accommodate a complicated relationship between variables and time-dependent behaviour better than mathematical modelling (Sterman 2000). There were two stages in constructing the costbenefit model before running the simulation. First, a causal loop diagram (CLD) was formulated. The CLD was then translated into a Stock Flow Diagram (SFD). The most extreme single case was simulated using STELLA 9.13 to explore the trade-off between the cost and the benefit of each improvement scenario. Finally, the results were compared using a costbenefit ratio.

\section{Data gathering}

The data collected in this study came from several sources. The 'hard' data sources were from official documents, such as meeting minutes, key performance indicators, sales reports, financial reports, complaint reports, and literature related to multiple cases in this study. Most of the 'hard' data were used to run

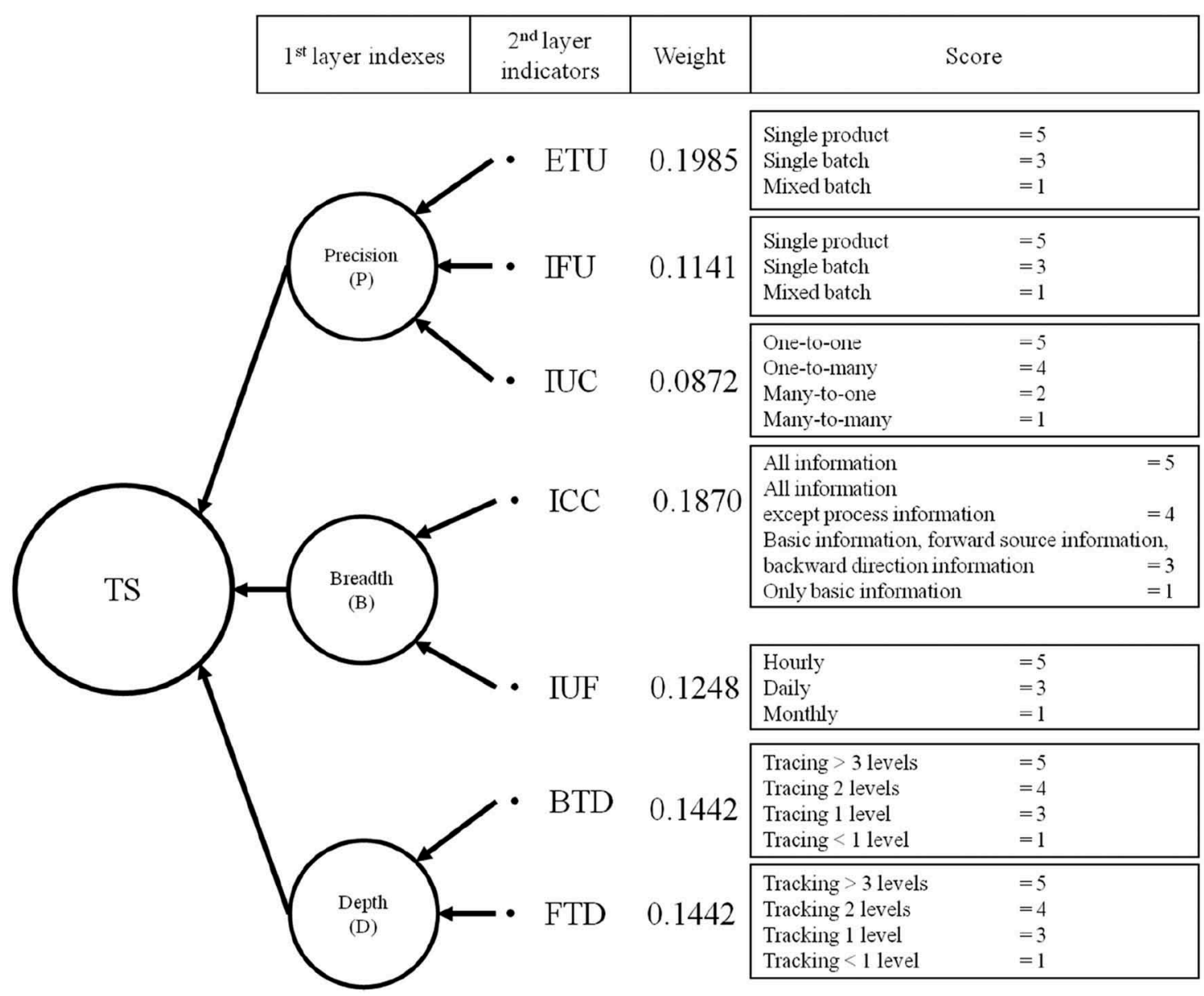

Figure 1. Granularity evaluation model. 
the system dynamic simulation. The 'soft' data sources were from the observations and interview results.

The interview for Case 1 was conducted on March $1^{\text {st }}, 2017$. The interviewee was a senior quality assurance manager who had an Industrial Engineering degree and seven years of work experience. The interview for Case 2 was conducted on July $6^{\text {th }}, 2017$. The interviewee was an experienced SHEQ (Safety, Health, Environment, and Quality) manager for seven years who had a bachelor degree from a related field and many professional certifications. The interview for Case 3 was conducted on October $3^{\text {rd }}, 2017$. The interviewee was a senior quality assurance manager who held a bachelor degree and had 21 years of work experience.

The interview guide in Table 2 was prepared with open-ended and closed questions to ensure consistency. Interviews were conducted face-to-face, one per interviewee, at a time and place specified by the interviewees and lasted for approximately 60 minutes. The interviews were recorded and transcribed. The transcripts were submitted to the interviewee and approved by the interviewee to ensure no change of intent.

Field observations were conducted to collect information regarding the TS of each case. The TS of each case was observed for about three months. Observation of the annual food recall simulation of each case provided deep understanding about the implementation of food recall procedures and the utilisation of the TS during food recalls. The collected information was used to construct a causal loop diagram. The data used to run the simulation was real data sets from the most extreme case.

\section{Results}

\section{Cross-case comparison and analysis}

A commodity industry focused on the production and sale of coconut cooking oil and palm cooking oil was chosen as Case 1 in this study. This industry has been operating in Indonesia since 1987 and sold its products mostly in bulk. This industry has been implementing ISO 22000:2005 standard of food safety management system since 2014. The industry realised that its TS was still weak because it sold its products using the spot market transaction model. Based on historical data, the recall cost per year of Case 1 ranged from $0-4.1 \%$ of its revenue.

Case 2 is an industry focused on palm cooking oil and started operating in Indonesia in 1993. The industry had more product mix than the industry in Case 1. Although it had a large market in packaged products, trading in bulk contributed the most to this industry. The industry in Case 2 has had ISO 9001 and HACCP (Hazard Analysis and Critical Control Point) certification since 2009. There was a specific department which focused on issues of quality management, food safety, environment, and occupational health and safety, namely the SHEQ department. This industry had experienced a total recall when a process failure occurred due to undetected filter damage during the production process. The recall cost per year of Case 2 ranged from $0-3.22 \%$ of its revenue.

Case 3 was not only the largest but also had operated for the longest compared with the two previous cases. The production process characteristics of Case 3 were the same as Case 2, but the derivative products mix was different. The industry in Case 3 has had ISO 22000:2005 certification since 1997. Thus, the level of maturity in implementing a food safety management system in Case 3 was also higher than the other two. However, recalls still occurred and the recall cost ranged between $0-3.04 \%$ of its revenue. Table 3 shows the comparison of each industry's demographics.

\section{Text analysis result}

Case 1 and Case 2 stated that different types of customers had different food safety awareness. Both

Table 2. Interview guide.

\begin{tabular}{|c|c|}
\hline Section of the interview & Questions \\
\hline \multirow[t]{7}{*}{ Company Demographics and Interviewee Information } & 1. In what year did this company start operating? \\
\hline & 2. What are your main products? \\
\hline & 3. How does your company sell the products: in bulk or packaged product? \\
\hline & 4. What is the customer mix and market composition for your products? \\
\hline & 5. What is your position in this company? \\
\hline & 6. How long have you worked here? \\
\hline & 7. What is your last education qualification? \\
\hline \multirow[t]{5}{*}{ Food Safety Awareness } & 1. What is the company's food safety system certification? \\
\hline & 2. In what year did this company get its food safety system certification? \\
\hline & 3. To what extent are your customers aware of food safety? \\
\hline & 4. To what extent is this company responsible for food safety? \\
\hline & 5. Are you willing to share a food safety incident that your company has been involved in? \\
\hline \multirow[t]{5}{*}{ TS implementation } & 1. To what extent is TS implemented in this company? \\
\hline & 2. Please describe the food safety team's role and responsibility! \\
\hline & 3. How often does your food safety team work? \\
\hline & 4. Please describe the traceability information system! \\
\hline & 5. How far can your TS trace or track a batch product? \\
\hline \multirow[t]{5}{*}{ Customer complaints and Product Recall } & 1. What can become a trigger for a product recall? \\
\hline & 2. Please describe the customer complaint situation for this company! \\
\hline & 3. How many customer complaints does your company receive in a typical year? \\
\hline & 4. What is your company's preventive recall strategy? \\
\hline & 5. Please describe the recall procedure in this company! \\
\hline
\end{tabular}


Table 3. Industry demographics.

\begin{tabular}{|c|c|c|c|}
\hline Category & Case 1 & Case 2 & Case 3 \\
\hline Started operation & 1987 & 1993 & 1962 \\
\hline Type of products & $\begin{array}{l}\text { RBDCNO (Coconut cooking oil) and RBDOlein } \\
\text { (Palm cooking oil) }\end{array}$ & $\begin{array}{l}\text { RBDOlein (Palm cooking oil) } \\
\text { and Margarine }\end{array}$ & $\begin{array}{l}\text { RBDOlein (Palm cooking oil), } \\
\text { Margarine, and Shortening }\end{array}$ \\
\hline Type of packaging & bulk and packaged product & bulk and packaged product & bulk and packaged product \\
\hline Customer mix & $50 \%$ local market, $50 \%$ export market & $\begin{array}{l}70 \% \text { local market, } 30 \% \text { export } \\
\text { market }\end{array}$ & $40 \%$ local market, $60 \%$ export market \\
\hline Total investment & < USD 15 million & $<$ USD 15 million & > USD 55 million \\
\hline $\begin{array}{l}\text { Company scale based on } \\
\text { total investment }\end{array}$ & Small & Small-medium & Large \\
\hline Total Employee(s) & 100 & 380 & 8,979 \\
\hline Status & Private company & Private company & Public company \\
\hline
\end{tabular}

agreed that industrial customers paid more attention than retailers. In Case 1, corporate responsibility arose as a result of customer requirements. Thus, it was implied that industrial objectives met the requirements of food safety management only to maintain and to develop market share. In Case 2, the responsibility depended on sales contracts, whether it was sold as is or sold with after sales service. This statement implied that the actual difference was not due to the customer category but the transaction model. Retailers bought products using a spot market model while industrial customers bought products using a contract model whether it was relational, simple, or long-term (Vo, Mainetti, and Fenies 2016). In Case 3 , the organisation implemented a food safety management system to provide a pathway for organisational development and to improve customer satisfaction. Since the HACCP standard categorised hazards as biological, physical, chemical, the edible oil industry rarely experienced biological hazards.

In Case 1 and 2, the food safety team was involved as part of TS. In contrast, in Case 3 the TS had been embedded into operational management. Case 1 and 2 mentioned the same things about food safety team responsibility. However, in Case 3, the food safety team responsibility was more comprehensive.

One dimension of TS is information system technology. Case 1 combined paper and digital methods in processing the traceability information. Case 2 had a tailor-made integrated information system and Case 3 used modular ERP (Enterprise Resource Planning) software. The information system influenced the speed of information collection. Case 1 measured its speed in days, Case 2 in hours, and Case 3 in minutes. All cases used the internal serial number to identify the product during the production process. However, each tank truck had been embedded with GPS technology to monitor product positioning outside the company area.

Case 1 and 2 received more than one complaint per month, while Case 3 could receive up to 3-4 times more complaints. In Case 1 and 2, complaint handling was focused only on correction. In fact, Case 3 was already oriented toward corrective action in handling the complaints. This situation had an impact on the issues faced in the handling of complaints. In Case 1, issues related to food safety became very wide, ranging from raw material issues to logistic issues. In Case 2, it was only concerned with the production process failure. In Case 3, the issue encountered was only related to undetected minor contamination which was identified as a 'black-spot'.

While Case 1 and Case 2 were concerned with how to address unintentional food safety issues, Case 3 had gone further to consider intentional food safety issues such as food terrorism. To improve the ability to deal with intentional issues, Case 3 provided food defence training for the food safety team. The food safety team in Case 3 had regular tasks. This was in contrast to Case 1 and 2, where food safety teams worked in situational conditions.

In the discussion on the issue of industry food recalls, Case 1 and Case 2 agreed that customer complaints became the trigger for most food recalls. However, for Case 3, the topic of food recall seemed more sensitive. Case 3 had a different definition related to a food recall. Case 3 considered the term food recall to be used in the total recall situation. Case 3 had not conducted any recent food recalls. However, Case 3 revealed there were returned products due to black spot findings. We categorised a returned product due to a black spot finding as a preventive recall. Case 3 believed that even the best system could not eliminate black spot findings. Focusing on how to prevent intentional food safety issues was more critical for Case 3.

\section{Traceability comparison}

\section{Case 1}

Storage tank management has an essential role in this type of industry to condition the product batch. Product held in the same storage tank is considered to be a batch product until the tank is cleaned within the specified time range. The current distribution management allowed the industry to fulfil an order from one customer from more than one tank. Therefore, we considered the external trace unit to be a mixed batch (ETU $=1)$. Moreover, the industry recognised that the number and capacity of storage tanks did not allow for perfect segregation between batches. Thus, the production planning did not 
Table 4. TS score comparison.

\begin{tabular}{|c|c|c|c|c|c|c|c|}
\hline \multirow[b]{2}{*}{ Second layer indicators } & \multirow[b]{2}{*}{ Weight (W) } & \multicolumn{3}{|c|}{ Score (S) } & \multicolumn{3}{|c|}{$W \times S \times 20$} \\
\hline & & Case 1 & Case 2 & Case 3 & Case 1 & Case 2 & Case 3 \\
\hline ETU & 0.1985 & 1 & 1 & 3 & 3.970 & 3.970 & 11.910 \\
\hline IFU & 0.1141 & 1 & 3 & 3 & 2.282 & 6.846 & 6.846 \\
\hline IUC & 0.0872 & 2 & 2 & 5 & 3.488 & 3.488 & 8.720 \\
\hline ICC & 0.1870 & 4 & 5 & 5 & 14.960 & 18.700 & 18.700 \\
\hline IUF & 0.1248 & 3 & 5 & 5 & 7.488 & 12.480 & 12.480 \\
\hline BTD & 0.1442 & 1 & 3 & 5 & 2.884 & 8.652 & 14.420 \\
\hline FTD & 0.1442 & 3 & 3 & 3 & 8.652 & 8.652 & 8.652 \\
\hline \multicolumn{2}{|c|}{ Total TS performance score $=$} & & & & 43.72 & 62.79 & 81.73 \\
\hline
\end{tabular}

consider from which tank the material was taken and where the product would be stored. Production planning focused only on quantity. This condition caused a mixed batch as well in the internal flow unit $($ IFU = 1). The identifiable unit conversion was manyto-one (IUC $=2$ ) because the raw material had to be collected for several periods before being processed. Besides, supplier capacity was not as significant as the industry's production capacity.

The company collected all the essential data to meet the requirements of the food safety management system (ICC $=4)$. However, the collection of process information was paper-based and not integrated. Since the recording system in this company combined paper and digital, some information was collected in paper form first and then input into the computer system. The collection process meant that the information updates into the system only happened once a day (IUF $=3$ ).

In Case 1, the purchase of raw materials was mostly made through brokers or consolidators so that tracing the source of raw materials was very difficult. Backward tracking distance could only reach up to brokers $(B T D=1)$. However, one level tracking could be done even if the buyer was a broker because the products were sent to the user rather than to the broker (FTD = 3).

\section{Case 2}

Similar to Case 1, a storage tank was considered to be a batch product. In this industry a customer's order did not need to be met from the same batch. The industry could do that well because better infrastructure than Case 1 supported it. The number of storage tanks was greater than Case 1 with varying capacities ranging from 600 tons to 3000 tons. Proper tank management is likely to support an improvement in the external trace unit of the industry. However, at the time we conducted the observation, the external trace unit was still considered a mixed batch $(E T U=1)$. The two stages of the production process namely refinery and fractionation supported clear batch separation so that the internal flow unit could be a single batch (IFU $=3$ ). The identifiable unit conversion was many-to-one (IUC $=2$ ) because the raw material had to be collected over several periods and from many suppliers.
The integrated information system played a role in collecting data as complete as possible (ICC $=5)$ and in real-time (IUF $=5$ ). The combination of the information system capability and the sourcing policy supported the industry to do one level tracing $(B T D=3)$ and one level tracking (FTD $=3$ ).

\section{Case 3}

Given the topic of bulk liquid industry, the maximum value for external trace unit $(E T U=3)$ and internal flow unit (IFU = 3) area single batch. The industry in Case 3 was capable of maintaining a single batch level due to strict hold and release product procedures as well as infrastructure. Vertical integration was the key to achieving the highest score in identifiable unit conversion (IUC = 5). The industry had backward integration to the plantation where the palm fruit was simultaneously harvested and processed into crude oil. The crude oil from the plantation area was then sent in an oil tanker to the factory. It was stored in one storage tank and processed to become one tank of the finished product.

The information system in Case 3 used Commercial Off-The-Shelf (COTS) ERP software from a reputable provider so that the data was complete $(I C C=5)$ and updated in real-time (IUF $=5$ ). The vertical integration also supported the backward tracing distance. The industry could trace the raw material to the plantation, the front of the food chain (BTD = 5). However, edible oil trading in bulk will always limit the tracking system only to one-step-forward (FTD $=3$ ). The summary of traceability comparison among three cases can be seen in Table 4.

\section{The cost-benefit model}

The cost-benefit model was developed to support the hypothesis that not all improvements in the dimensions of TS will deliver a significant impact in the short-term. The cost-benefit model was built using a system dynamics approach in two steps. First, the relationships among elements in a CLD were mapped. Figure 2 illustrates the CLD of the cost-benefit model. Feedback loops in the diagram indicate complexity. One of the loops is Profit $\rightarrow(+)$ Improvement budget $\rightarrow(+)$ Breadth improvement $\rightarrow(-)$ Recall time $\rightarrow(+)$ Recall cost $\rightarrow(-)$ Profit. 


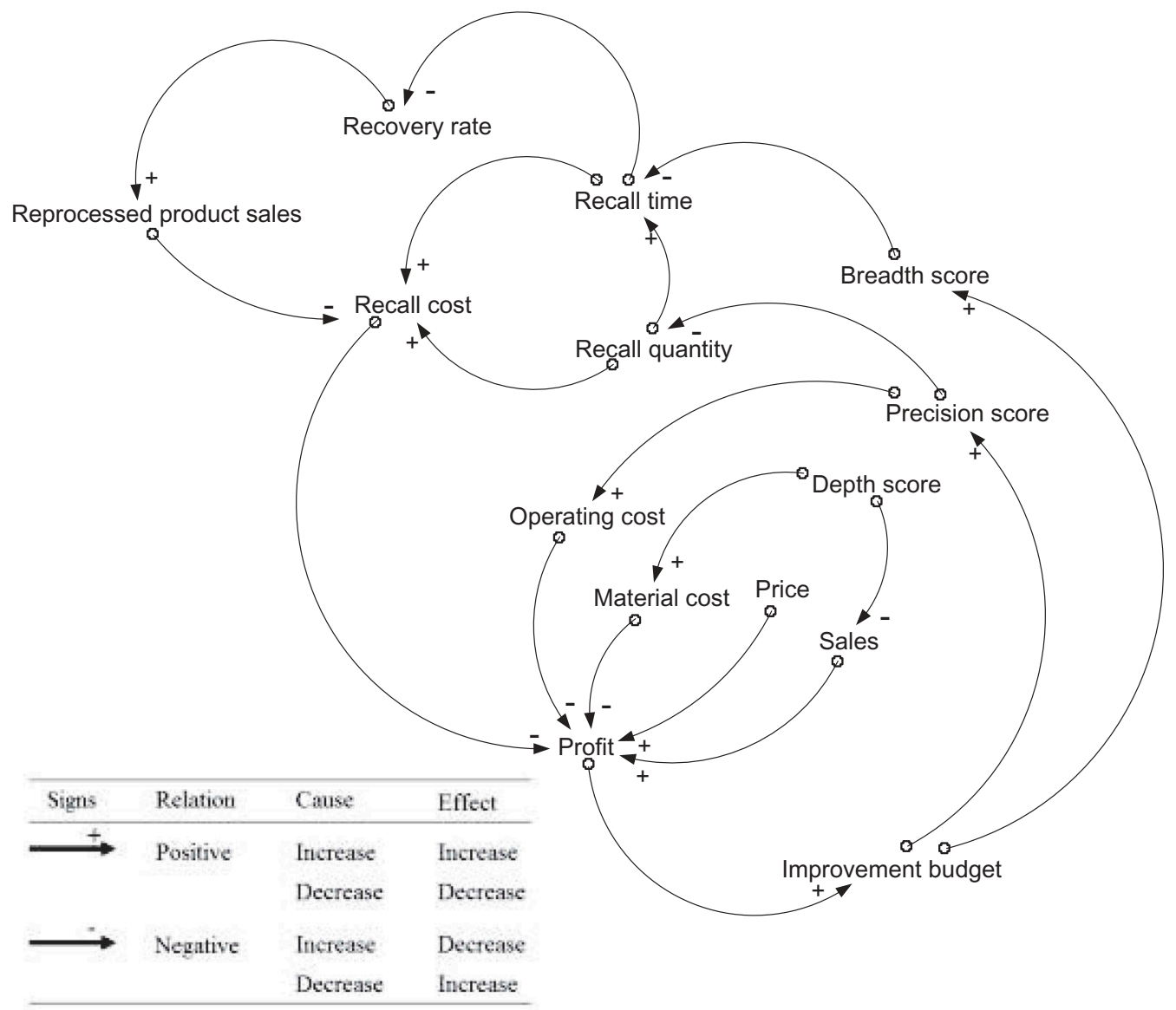

Figure 2. The causal loop diagram.

Improving TS requires investing a cost allocation. This cost is budgeted from the profits earned by an industry. The higher the profit earned by the industry, the higher the investment that can be budgeted for improvement. This budget can be used by the industry to increase its breadth score. If the score increases, the recall time will decrease and it will reduce recall cost. In the end, a low recall cost will increase the company's profit. The assumptions made in the simulation model are that reprocessing is the only option to recover a recalled product, and all recalled products can be reprocessed.

The next step was to construct a SFD based on elements in the CLD. The elements in the CLD were translated to become variables (see Table 5). The simulation of cost-benefit for TS improvement was run based on the SFD in Figure 3. This paper primarily presents a simulation study on Case 1 in seven scenarios. This was based on the results of the traceability comparison in Table 1 which showed that the urgency for improving the TS was in Case 1.

\section{Scenarios for TS improvement}

Scenarios were developed to answer the 'what-if' question of improving each dimension of TS based on GEM. The data used in the simulation for Case 1 was monthly operational data from 2014. In that year there were three voluntary-partial-trade recalls that occurred in March, July and November.

Scenario 1 is the existing TS condition of Case 1. Scenario 2 is to improve Case 1's precision score by making Case 3 the benchmark. ETU and IFU are expected to become a single batch and manage IUC to be one-to-one. Scenario 3 is to improve Case 1's breadth score by making Case 2 the benchmark. ICC becomes all information and IUF becomes hourly. Scenario 4 is to improve Case 1's depth score by making Case 2 the benchmark. BTD becomes onelevel, and FTD becomes one-level following the minimum requirements of ISO 22000. Figure 4 shows the operational strategies to improve the score in each scenario. Scenarios 5 to 7 are combinations of two single scenarios. Scenario 5 is a combination of scenarios 2 and 3, scenario 6 is a combination of scenarios 2 and 4 , while scenario 7 is a combination of scenarios 3 and 4 .

After simulating each scenario in a cycle of 12 months, the benefit-cost ratio was calculated using Equation (1). The cost is the difference between the total cost at each improvement scenario and the recall cost at each improvement scenario as in 


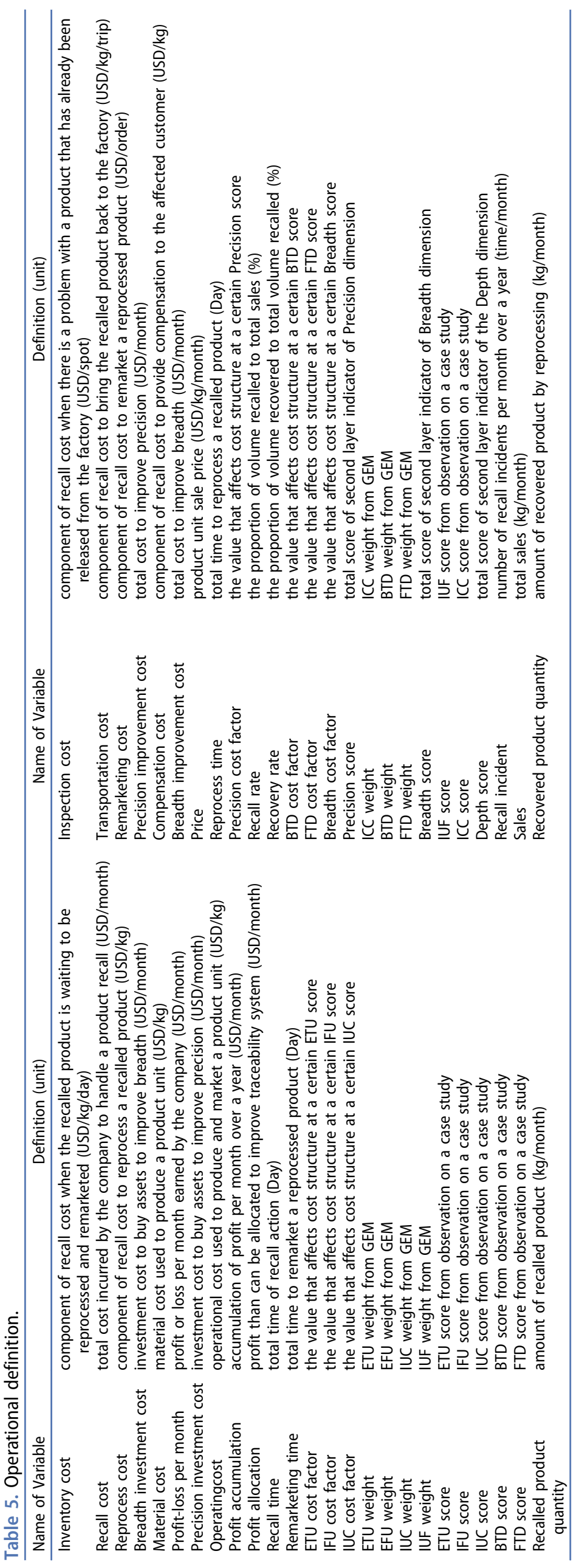




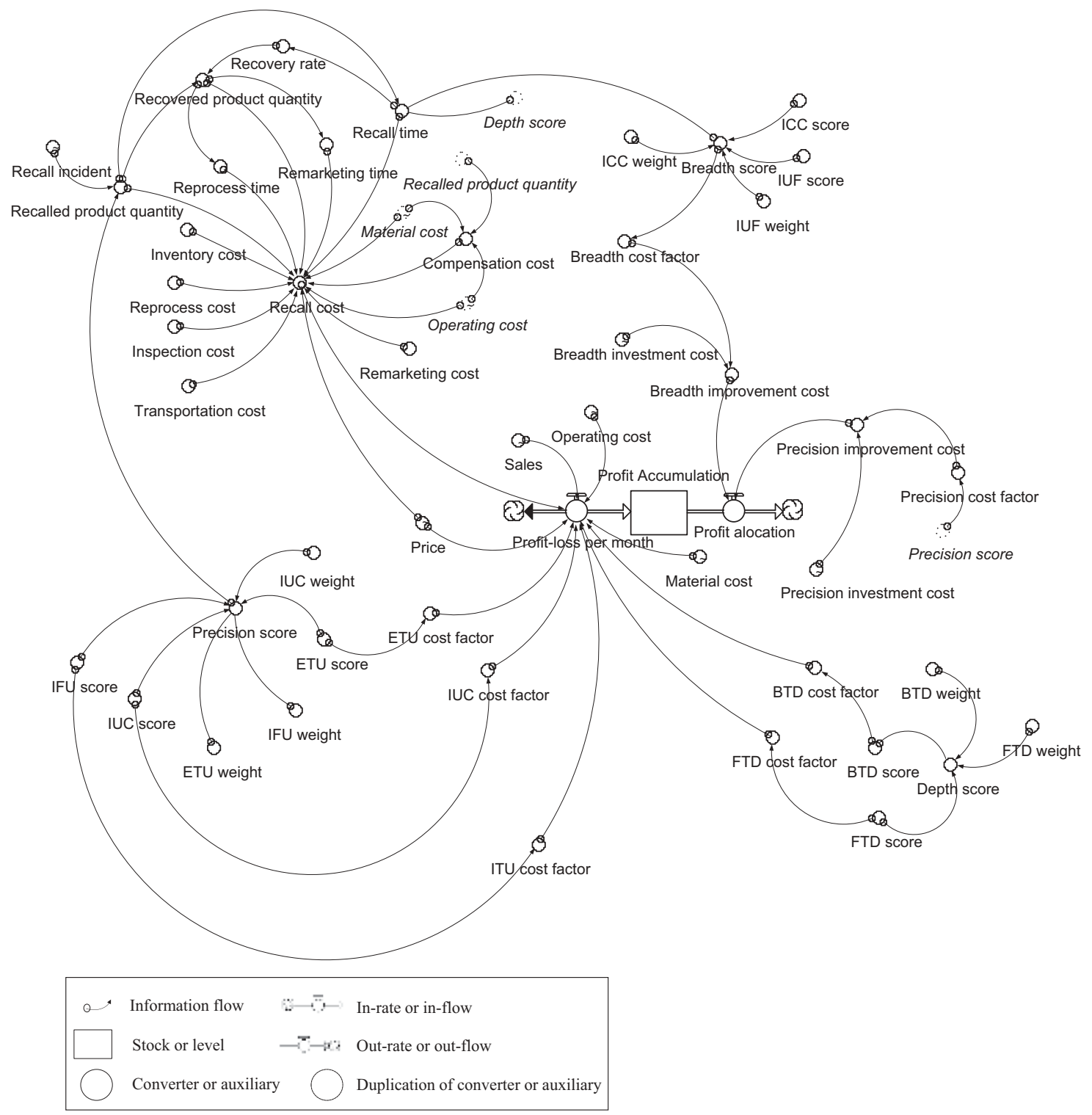

Figure 3. The stock flow diagram.

Equation (2). The benefit is the difference between the recall cost for existing conditions and the recall cost for each improvement scenario as in Equation (3).

$$
\begin{gathered}
B / C \text { ratio }_{(j)}=\text { Benefit }_{(j)} / \text { Cost }_{(j)} \\
\text { Cost }_{(j)}=\sum_{t=1}^{12} \text { Total cost }_{j}-\sum_{t=1}^{12} \text { Recall cost }_{j} \\
\text { Benefit }_{(j)}=\sum_{t=1}^{12} \text { Recall cost }_{1}-\sum_{t=1}^{12} \text { Recall cost }_{j}
\end{gathered}
$$

where

$$
\begin{aligned}
& \mathrm{j}=\text { scenario }(2,3, \ldots, 7) . \\
& \mathrm{t}=\text { monthly period. }
\end{aligned}
$$

As seen in Table 6, the benefit-cost ratios were ranked from the largest to the smallest. The largest benefit-cost ratio is scenario 3 , which is to improve breadth score. Scenario 3 does not only show the largest benefit-cost ratio, but also has a positive impact on the company's profit at the end of the cycle (see Table 7). Surprisingly, implementing scenario 4 and 7 cause a decrease in profit while scenarios 2, 5, and 6 will actually cause the company to experience losses at the end of the period. Therefore, scenario 3 is the best proposed TS improvement program for Case 1 in the short-term. This result supports our hypothesis.

\section{Conclusion}

The proposed methodology has succeeded in providing a deep understanding of TS and the influence on food recall. The study of three bulk-liquid industries, called Case 1, Case 2, and Case 3, indicates that industry demographics can affect perspectives on food safety awareness, TS, customer complaints, and 


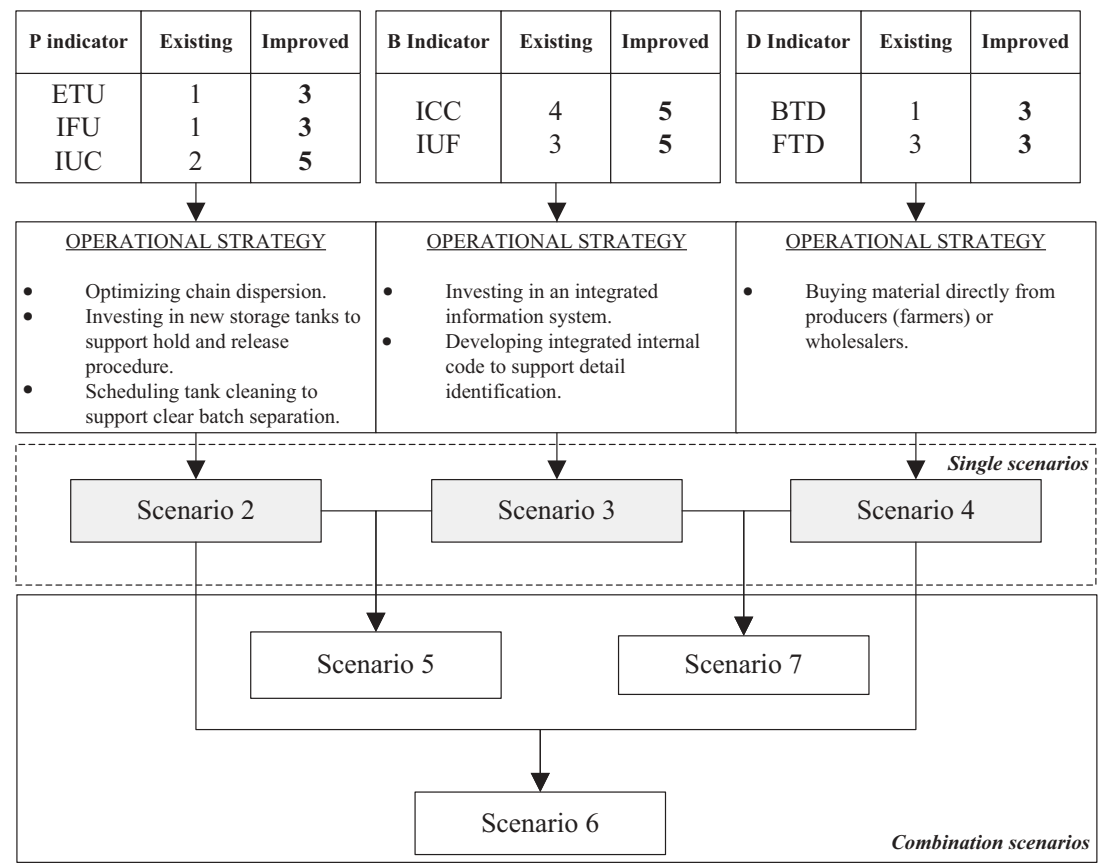

Figure 4. Case 1 simulation scenario.

Table 6. Benefit-cost ratio comparison.

\begin{tabular}{lrccc}
\hline Scenario & \multicolumn{1}{c}{ Benefit $(\$)$} & Cost $(\$)$ & B/C Ratio & Rank \\
\hline 3 & $731,692.31$ & $30,955,013.46$ & 0.023637 & 1 \\
5 & $1,177,576.92$ & $49,823,351.59$ & 0.023635 & 2 \\
7 & $740,923.08$ & $31,882,467.88$ & 0.023239 & 3 \\
6 & $1,082,538.46$ & $50,737,729.09$ & 0.021336 & 4 \\
2 & $994,423.08$ & $49,810,274.66$ & 0.019964 & 5 \\
4 & $352,000.00$ & $31,869,390.96$ & 0.011045 & 6 \\
\hline
\end{tabular}

Table 7. Profit accumulation in a cycle of 12 months.

\begin{tabular}{lc}
\hline Scenario & Profit accumulation \\
\hline 1 & $\$ 2,512,998.08$ \\
2 & $\$(15,360,916.97)$ \\
3 & $\$ 3,231,613.46$ \\
4 & $\$ 1,937,543.65$ \\
5 & $\$(15,190,840.05)$ \\
6 & $\$(16,200,256.01)$ \\
7 & $\$ 2,304,159.04$ \\
\hline
\end{tabular}

food recall. Case 3, representing a large-scale bulkliquid industry, took the initiative to improve its food safety management system to the highest level. However, the purpose of improving the TS in each case was based on the same reason, to reduce the impact of an adverse food recall. Case 3 placed more importance on intentional food safety issues while Case 1 and 2 put more emphasis on food recall due to unintentional issues.

A system dynamics approach was used to perform cost-benefit analysis in determining the best scenario to improve the TS. A simulation study was successfully performed for Case 1 and rated as scenario 3 was the best short-term improvement program and should be implemented by developing an integrated internal code and an integrated information system.
The theoretical significance of this study is the use of a cost-benefit model in improving TS in the bulkliquid food industry. For general purposes, this costbenefit model may well represent the same problem in any industry. The combination of a system dynamics approach and GEM in building a costbenefit model is a substantial contribution to this work. The simulation results for each scenario have managerial implications. Even though precision improvement can significantly reduce recall cost, it is advisable for the bulk-liquid food industry to consider the right time to improve precision. This is because the results indicate that all scenarios which involve precision improvement cause the industry to experience losses at the end of cycle.

Some limitations should be recognised acknowledged with respect to this study. The recall cost calculation was based on the assumption that reprocessing was the only option to recover the recalled product and all recalled products could be reprocessed. It would be preferable in future research to consider all options of product recovery such as downgrading or redirecting for other use. The recall incidents used in the simulation were voluntarypartial-trade recalls, so it did not involve the end consumer and mass media factors. Therefore, one of the guidelines for further research is to develop a model for consumer recall in the bulk-liquid industry.

\section{Disclosure statement}

No potential conflict of interest was reported by the authors. 


\section{Notes on contributors}

Ivan Gunawan is currently a PhD candidate in Logistics and Supply Chain Engineering in the Department of Industrial Engineering at Institut Teknologi Sepuluh Nopember (ITS), Surabaya, Indonesia. He received a bachelor's degree in Industrial Engineering from Universitas Katolik Widya Mandala Surabaya (UKWMS) and a master's degree in Technology Management from ITS. His research interests are in food supply chain and quality management. During past few years, he has provided lectures in statistical quality control, operations research, and industrial system simulation to undergraduate level at UKWMS.

Iwan Vanany is a Professor of Business Process Reengineering in the Department of Industrial Engineering at Institut Teknologi Sepuluh Nopember (ITS), Surabaya, Indonesia. He received his $\mathrm{PhD}$ degree from Universiti Teknologi Malaysia (UTM) in Manufacturing and Industrial Engineering and both Master's and Bachelor's degrees in Industrial Engineering Department from ITS. His research interests are in the business process management, food supply chain management, and operations management. He has published in International Journal of Information System and Supply Chain Management, Meiji Business Journal, Supply Chain Forum: An International Journal, International Journal Logistics Systems and Management, Journal of Islamic Marketing, and International Journal of Lean Six Sigma. He teaches business process reengineering, supply chain management, enterprise resources planning (ERP), logistics management, and productions and planning control.

Erwin Widodo was granted his Master Degree from Ritsumeikan University of Kyoto and his Doctoral Degree from Hiroshima University both in Japan, in 2006 and 2012 respectively. His expertise is of multi-player decision-making in industry especially by using game theory. In this current period of 2016-2020, he is assigned as postgraduate program coordinator in his institution, namely Industrial Engineering Department of Institut Teknologi Sepuluh Nopember (ITS), Surabaya, Indonesia. He actively joins several international associations related to his field, i.e. IDGS, Informs, IAEng, IEOM and the likes. Moreover, he also joins as board member in several international journals such as IJISE, OSCM, IJTech, Cogent Engineering, etc.

\section{References}

Aiello, G., M. Enea, and C. Muriana. 2015. "The Expected Value of the Traceability Information." European Journal of Operational Research 244 (1): 176-186. doi:10.1016/j. ejor.2015.01.028.

Asioli, D., A. Boecker, and M. Canavari. 2014. "On the Linkages between Traceability Levels and Expected and Actual Traceability Costs and Benefits in the Italian Fishery Supply Chain." Food Control 46: 10-17. doi:10.1016/j.foodcont.2014.04.048.

Banerjee, R., H. Menon, and K. Ramful. 2015. "Traceability in Food and Agricultural Products." International Trade Centre Bulletin 91. Accessed 28 February 2018. http:// www.intracen.org/uploadedFiles/intracenorg/Content/ Exporters/Exporting_Better/Quality_Management/ Redesign/EQM\%20Bulletin\%2091-2015_Traceability_ FINAL\%20140ct15_web.pdf
Bendaoud, M., C. Lecomte, and B. Yannou. 2007. "Traceability Systems in the Agri-Food Sector: A Functional Analysis." Accessed 2 July 2018. https://www.designsociety.org/pub lication/25759/Traceability+Systems+in+the+Agri-Food + Sector\%3A+a+Functional+Analysis

Chryssochoidis, G., A. Karagiannaki, K. Pramatari, and O. Kehagia. 2009. "A Cost-Benefit Evaluation Framework of an Electronic-Based Traceability System." British Food Journal 111 (6): 565-582. doi:10.1108/00070700910966023.

Dabbene, F., and P. Gay. 2011. "Food Traceability Systems: Performance Evaluation and Optimization." Computers and Electronics in Agriculture 75 (1): 139-146. doi:10.1016/j.compag.2010.10.009.

Dani, S. 2015. Food Supply Chain Management and Logistics: From Farm to Fork. London: Kogan Page Publishers.

Donnelly, K. M., M. Thakur, and J. Sakai. 2013. "Following the Mackerel-Cost and Benefits of Improved Information Exchange in Food Supply Chains." Food Control 33 (1): 25-31. doi:10.1016/j.foodcont.2013.01.021.

FSANZ. 2014. "Food Industry Recall Protocol." Accessed 28 February 2018. www.foodstandards.gov.au/media/docu ments/Food\%20Recall_WEB.pdf

FSIS (Food Safety and Inspection Service) 2017. "Summary of Recall Cases." Accessed 28 February 2018. https://www. fsis.usda.gov/wps/portal/fsis/topics/recalls-and-publichealth-alerts/recall-summaries

Golan, E. H., B. Krissoff, F. Kuchler, L. Calvin, K. Nelson, and G. Price 2004. "Traceability in the US Food Supply: Economic Theory and Industry Studies. United States Department of Agriculture, Economic Research Service." Research Report 33939, Accessed 28 February 2018. https:// ageconsearch.umn.edu/bitstream/33939/1/ae040830.pdf

Hora, M., H. Bapuji, and A. V. Roth. 2011. "Safety Hazard and Time to Recall: The Role of Recall Strategy, Product Defect Type, and Supply Chain Player in the US Toy Industry." Journal of Operations Management 29 (7): 766-777. doi:10.1016/j.jom.2011.06.006.

International Organization for Standardization. 2005. Food Safety Management Systems-Requirements for Any Organization in the Food Chain ISO 22000:2005. Geneva: International Organization for Standardization.

Jansen-Vullers, M., C. van Dorp, and A. J. Beulens. 2003. "Managing Traceability Information in Manufacture." International Journal of Information Management 23 (5): 395-413. doi:10.1016/s0268-4012(03)00066-5.

Kang, Y. S., I. H. Park, and S. Youm. 2016. "Performance Prediction of a Mongodb-Based Traceability System in Smart Factory Supply Chains." Sensors 16 (12): 2126. doi:10.3390/s16122126.

Karâa, M., and J. Morana. 2016. "The Determinants Leading to the Adoption of Traceability: Adaptation to the Tunisian Date Sector." Supply Chain Forum: an International Journal 17 (1): 3-14. doi:10.1080/16258312.2016.1143205.

Kiani, B., H. Shirouyehzad, F. Khoshsaligheh Bafti, and H. Fouladgar. 2009. "System Dynamics Approach to Analysing the Cost Factors Effects on Cost of Quality." International Journal of Quality \& Reliability Management 26 (7): 685-698. doi:10.1108/02656710910975750.

Kim, S., and S. Wook Kim. 2010. "The Trade-Off of Service Quality and Cost: A System Dynamics Approach." Asian Journal on Quality 11 (1): 69-78. doi:10.1108/15982681011051831.

Kumar, S. 2014. "A Knowledge Based Reliability Engineering Approach to Manage Product Safety and Recalls." Expert Systems with Applications 41 (11): 5323-5339. doi:10.1016/ j.eswa.2014.03.007.

Kumar, S., and E. M. Budin. 2006. “Prevention and Management of Product Recalls in the Processed Food Industry: A Case 
Study Based on an Exporter's Perspective." Technovation 26 (5-6): 739-750. doi:10.1016/j.technovation.2005.05.006.

Li, C. 2013. "Cost and Benefit Analysis of Traceability in Egg Supply Chain-Case Study." Master thesis, Accessed 2 July 2018. https://thesis.eur.nl/pub/14291/MA-Thesis-Chang.pdf

Li, T., J. C. Bernard, Z. A. Johnston, K. D. Messer, and H. M. Kaiser. 2017. "Consumer Preferences before and after a Food Safety Scare: An Experimental Analysis of the 2010 Egg Recall." Food Policy 66: 25-34. doi:10.1016/j. foodpol.2016.11.008.

Lu, C., and Y. Zhang. 2010. "Reformation of Voluntary Food Recall System from the Angle of the Theory of Risk Society." Agriculture and Agricultural Science Procedia 1: 296-300. doi:10.1016/j.aaspro.2010.09.037.

Mai, N., S. Gretar Bogason, S. Arason, S. Víkingur Árnason, and T. Geir Matthíasson. 2010. "Benefits of Traceability in Fish Supply Chains-Case Studies." British Food Journal 112 (9): 976-1002. doi:10.1108/00070701011074354.

Mari Karlsen, K., P. Olsen, and K. A. M. Donnelly. 2010. "Implementing Traceability: Practical Challenges at a Mineral Water Bottling Plant." British Food Journal 112 (2): 187-197. doi:10.1108/00070701011018860.

Min, H. 1989. "A Bicriterion Reverse Distribution Model for Product Recall." Omega 17 (5): 483-490. doi:10.1016/ 0305-0483(89)90044-3.

Nääs, I. D. A., M. Mollo Neto, O. Vendrametto, and S. A. Canuto. 2015. "Comparative Analysis of Different Meat Traceability Systems Using Multiple Criteria and a Social Network Approach." Engenharia Agrícola 35 (2): 340-349. doi:10.1590/1809-4430-eng.agric.v35n2p340-349/2015.

NADFC (National Agency for Drug and Food Control) 2017. Peraturan Kepala Badan Pengawas Obat dan Makanan Republik Indonesia tentang Penarikan Pangan dari Peredaran, No. 22 [Regulation of the Head of National Agency for Drug and Food Control about Food Recall, No. 22]. Accessed 2 July 2018. http://jdih.pom.go.id/ showpdf.php?u=D5NzNeqzDCCvjty1 Aklwjc7CFFm\% 2F2jlfNNxDGgMSlu4\%3D

Ni, J. Z., B. B. Flynn, and F. R. Jacobs. 2014. "Impact of Product Recall Announcements on Retailers' Financial Value." International Journal of Production Economics 153: 309-322. doi:10.1016/j.ijpe.2014.03.014.

Qian, J., B. Fan, X. Wu, S. Han, S. Liu, and X. Yang. 2017. "Comprehensive and Quantifiable Granularity: A Novel Model to Measure Agro-Food Traceability." Food Control 74: 98-106. doi:10.1016/j.foodcont.2016.11.034.

Rehben, E. 2015. "Cost and Value of Animal Identification and Traceability along the Agrifood Supply Chain." Accessed 2 July 2018. https://www.icar.org/wp-content /uploads/2015/12/Rehben.pdf

Roth, A. V., A. A. Tsay, M. E. Pullman, and J. V. Gray. 2008. "Unraveling the Food Supply Chain: Strategic Insights from China and the 2007 Recalls." Journal of Supply Chain Management 44 (1): 22-39. doi:10.1111/j.1745493x.2008.00043.x.

Roth, M., and R. Dolschitz. 2007. "Cost-Benefit-Analysis of Quality- and Traceability Systems in Supply Chains of Animal Products." Accessed 2 July 2018. http://www.informa tique-agricole.org/download/efita-conference/Congres_ EFITA_2007/tuesday/1400/business_theme-quality_and_tra ceability/fullpaper_efita_2007_mroth_20070330092223.pdf
Sahin, E., Y. Dallery, and S. Gershwin. 2002. Performance Evaluation of a Traceability System. An Application to the Radio Frequency Identification Technology. In Systems, Man and Cybernetics, 3 vols. 6. IEEE. doi:10.1109/icsmc.2002.1176118.

Shi, L. K., D. D. Zhang, and Y. L. Liu. 2016. "Incidence and Survey of Polycyclic Aromatic Hydrocarbons in Edible Vegetable Oils in China." Food Control 62: 165-170. doi:10.1016/j.foodcont.2015.10.037.

Skoglund, T., and P. Dejmek. 2007. "Fuzzy Traceability: A Process Simulation Derived Extension of the Traceability Concept in Continuous Food Processing." Food and Bioproducts Processing 85 (4): 354-359. doi:10.1205/fbp07044.

Sparling, D., S. Henson, S. Dessureault, and D. Herath. 2006. "Costs and Benefits of Traceability in the Canadian Dairy-Processing Sector." Journal of Food Distribution Research 37 (1): 160-166.

Sterman, J. D. 2000. Business Dynamics: Systems Thinking and Modeling for a Complex World. New York: Mc Graw-Hill.

Taylor, E. 2001. "HACCP in Small Companies: Benefit or Burden?" Food Control 12 (4): 217-222. doi:10.1016/ s0956-7135(00)00043-8.

Thakur, M., and C. R. Hurburgh. 2009. "Framework for Implementing Traceability System in the Bulk Grain Supply Chain." Journal of Food Engineering 95 (4): 617-626. doi:10.1016/j.jfoodeng.2009.06.028.

Trafialek, J., and W. Kolanowski. 2017. "Implementation and Functioning of HACCP Principles in Certified and Non-Certified Food Businesses: A Preliminary Study." British Food Journal 119 (4): 710-728. doi:10.1108/bfj-072016-0313.

Trienekens, J., and P. Zuurbier. 2008. "Quality and Safety Standards in the Food Industry, Developments and Challenges." International Journal of Production Economics 113 (1): 107-122. doi:10.1016/j.ijpe.2007.02.050.

Van der Vorst, J. G. A. J. 2004. "Performance Levels in Food Traceability and the Impact on Chain Design: Results of an International Benchmark Study." In Dynamics in Chains and Networks: Proceedings of the Sixth International Conference on Chain and Network Management in Agribusiness and the Food Industry, edited by Harry Bremmers, Onno Omta, Jaques Trienekens, and Emiel Wubben, 175-183. Wageningen: Wageningen Academic Press.

Vanany, I., and S. Zailani. 2010. "Urgency in Managing the Risk in Supply Chain among Indonesian Manufacturing Companies." International Business Management 4 (4): 199-208. doi:10.3923/ibm.2010.199.208.

Vo, V. D., N. Mainetti, and P. Fenies. 2016. “Traceability and Transaction Governance: A Transaction Cost Analysis in Seafood Supply Chain." Supply Chain Forum: an International Journal 17 (3): 125-135. doi:10.1080/ 16258312.2016.1188588.

Zhang, J., and T. Bhatt. 2014. "A Guidance Document on the Best Practices in Food Traceability." Comprehensive Reviews in Food Science and Food Safety 13 (5): 1074-1103. doi:10.1111/1541-4337.12103.

Zhu, L. 2017. "Economic Analysis of a Traceability System for a Two-Level Perishable Food Supply Chain." Sustainability 9 (5): 682. doi:10.3390/su9050682. 